\title{
Editor's Note: Special Issue on Embedded Computer Systems: Architectures, Modeling and Simulation
}

(c) Springer Science+Business Media, LLC, part of Springer Nature 2018

International Journal of Parallel Programming gratefully acknowledges the editorial work of the scholars listed below on the special issue entitled "Embedded Computer Systems: Architectures, Modeling and Simulation."

\section{Carlo Galuzzi}

Maastricht University

The Netherlands

\section{Hartwig Jeschke}

Leibniz University of Hannover

Germany

\section{Olli Silvén}

University of Oulu

Finland

\section{Dimitrios Soudris}

National Technical University of Athens (NTUA)

Greece

\section{Ioannis Sourdis}

Chalmers University of Technology

Sweden

Publisher's Note Springer Nature remains neutral with regard to jurisdictional claims in published maps and institutional affiliations. 